\title{
Influence of external conditions on the combinatorial processes at agamospermy
}

\author{
Evgenii Vladimirovich Levites, Svetlana Sergeevna Kirikovich
}

Institute of Cytology and Genetics, Siberian Branch of the Russian Academy of Sciences, Novosibirsk, Russia

Email: elevites@ngs.ru, svetak@, bionet.nsc.ru

Received 10 August 2013; revised 10 September 2013; accepted 10 October 2013

Copyright (C) 2013 Evgenii Vladimirovich Levites, Svetlana Sergeevna Kirikovich. This is an open access article distributed under the Creative Commons Attribution License, which permits unrestricted use, distribution, and reproduction in any medium, provided the original work is properly cited.

\begin{abstract}
The estimation of the influence of external conditions on marker enzymes phenotypic classes ratios in agamospermous sugar beet progenies has been carried out. It has been shown that different ways of flowering sugar beet plant branches isolation lead to different ratios of marker enzyme phenotypes in a developing agamospermous seed progeny. The obtained data are an additional confirmation of the hypothesis about the presence of differential chromosomes polyteny and its dependence on external conditions.
\end{abstract}

Keywords: Isozymes; Polyteny; Diminution; Agamospermy; Sugar Beet

\section{INTRODUCTION}

Different populational characteristics, such as the degree of variability in sexual and asexual plant populations [1, 2], were analyzed in numerous experimental and theoretical research activities devoted to agamospermy; the level of apomixis in a plant population [3] was also evaluated. Only in 1994-1996, there were contributions that initiated studying the mechanisms underlying agamospermous progenies variability $[4,5]$. According to the conclusions made by the authors, the observed ratios are conditioned by meiosis in polyploid cells of mother plant capable of agamospermous reproduction. For the cases when a mother plant was polyploid, such conclusion, on the whole, can be thought of regular, though a way to this understanding has turned quite long. In cases when a mother plant was diploid, the phenotypic classes ratio was determined by the meiosis that proceeds in tetraploid cells present as an admixture among the bulk of diploid cells [5]. For instance, it was shown that, in the agamospermous progeny obtained from diploid sugar beet plants, the phenotypic ratio on hypocotyl coloring was 11 color- ed: 3 uncolored; and the phenotypic ratio on isozyme markers was often equal to $3: 8: 3$, which corresponded to the tetraploid gametic segregation [5-7]. The process of such progenies formation was called meiotic agamospermy [8].

Isozymes have become a convenient instrument for studying agamospermy. A wonderful peculiarity of isozymes is their codominant inheritance due to which the hybrid plant isozyme spectrum is different from each parent isozyme spectrum. For instance, one isozyme with fast or slow electrophoretic mobility, which corresponds to the genotype of the given locus, is revealed in the electrophoregram for the homozygote on the gene controlling this marker enzyme. But both enzyme allelic variants (isozymes) and also hybrid isozymes [9,10] are revealed in the heterozygote. This allows one to reveal all 3 phenotypic classes in the progeny of plant heterozygous on the isozyme locus: two homozygous and one heterozygous. Assisted with isozymes, the case of mitotic agamospermy, at which the progeny developing in diploid sugar beet plant was monomorphous on the marker enzyme heterozygous phenotype, was revealed. This monomorphism on the heterozygous enzyme phenotype was indicative of the absence of meiotic genome transformations of cells capable of agamospermous reproduction [11]. At the same time, the polymorphism of this progeny on the other marker enzyme indicated the presence of a specific variability mechanism. To explain this phenomenon, a hypothesis that implies: a) the presence of differential chromosome polyteny, i.e. separate chromosome sites polytenization including those that carry this marker locus alleles in plant generative organs cells, b) random equiprobable attachment of two allelic copies (one copy from each chromosome of two homologous in a diploid plant) to the nuclear membrane or the nuclear matrix of the cell before its entering embryogenesis (this allelic pair then determines the genotype of a developing em- 
bryo), c) cell transition to embryogenesis and duplication of chromosomes attached to the nuclear membrane, d) first division of embryogenesis and diminution (loss) of unattached allelic gene copies $[12,13]$ was proposed. Occasional equiprobable attachment of allelic copies of chromatide regions is a combinatorial process that implies the existence of a mutual exchange by chromatide regions among chromosomes.

The data on marker enzymes phenotype ratios in agamospermous progenies of tri- and diploid sugar beet plants were the confirmation for the statements of this hypothesis $[14,15]$. The existence of specific phenotypic classes ratios in agamospermous progenies of diploid sugar beet plants has become a weighty argument not only in favor of the hypothesis about the presence of polyteny, but it also pointed out a mutual exchange of chromatide regions among chromosomes in the cell before its entering embryogenesis [15]. Initially, this hypothesis was proposed to explain sugar beet seeds phenotypic ratios obtained by mitotic agamospermy from nucellus somatic cells or integuments $[12,13]$. However, it was noticed that the same hypothesis is applicable also for the analysis of meiotic agamospermy when polyteny occurs in mother megaspore cells (MMC) $[14,16]$.

To characterize the polytene state of this or that chromosome site, we proposed the term "locus polygenotype" and the legend, e.g. $F_{n} S_{m}$, to describe its allelic composition, number of chromosomes and chromatides carrying each of the alleles [14]. The presented legend is suitable for a diploid cell but, in the case of a tetraploid, it can be $F_{n} F_{n} S_{m} S_{m}$.

The polyteny that affects the phenotypic ratio in agamospermous progenies is the result of a big and complicated DNA replication process which, as any enzymatic process, depends on many conditions. In this connection, studying the influence of external conditions on the phenotypic ratios in agamospermous progenies is of great interest. Earlier we carried out investigation regarding this point, and it was shown that colchicine or Triton X100 treatment $[15,17]$ affects sugar beet plant phenotypic classes ratios.

Earlier, we also obtained the facts that evidence the non-random distribution of isozyme phenotypes in the seeds analyzed in the order they set on a sugar beet plant branch. The non-random phenotypic distribution allowed us to hypothesize on the influence of external conditions on the degree of polyteny in the cells capable of entering embryogenesis and, respectively, on the geno- and phenotype ratios of an agamospermous progeny [18]. In the connection with the above-formulated, it was necessary to widen the scope of the investigation devoted to the influence of external conditions on the geno- and phenotypic ratios in agamospermous sugar beet progenies, and that was the aim of this contribution.

\section{MATERIAL AND METHODS}

The agamospermous progenies obtained from pollensterile sugar beet plants in the pollenless regime were involved in the investigation. Only plants of phenotype ms0 and ms1 on Owen classification [19] were left in the field to create the pollenless regime during flowering; individual isolators were also used. Two types of isolators were used to estimate the effect of environmental conditions for each experimental plant; part of plant branches was covered with an unbleached calico and part of branches - with parchment isolators.

The ratios of enzyme phenotypic classes of alcohol dehydrogenase (ADH1, E.C. 1.1.1.1.), malic enzyme (ME1, E.C. 1.1.1.40), isocitrate dehydrogenase (IDH3, E.C. 1.1.1.42) were analyzed with the method of electrophoresis in starch gel with a further isozymes histochemical staining in electrophoregrams [20,21].

Comparison of marker enzymes phenotypic classes ratios in seeds obtained at various ways of isolation was carried out using the G-criterion [22].

To determine locus enzyme polygenotypes, the revealed phenotypic classes ratios were compared to theoretical calculations obtained for a different polytenized allelic copies number in heterozygous enzyme loci. Theoretical calculations were realized, implying the variation of polytenized copies per allele in the interval of $2-8$.

According to the accepted hypothesis, polymorphism in agamospermous progenies was determined by the combinatorial process based on a random, equiprobable allelic copies attachment to the nuclear membrane $[12,13]$. This combinatorial process can be described by hypergeometrical probability distribution formulas $[23,24]$. According to these formulas, the portion of homozygotes is determined by a number of combinations - two from the number of the corresponding allelic copies accumulated as a result of polytenization. For example, if one allele is presented by $n$ copies in the diploid cell, the other oneby $m$ copies; then the portion of homozygotes (homoallelic genotypes) on the first allele is determined with the formula: $C_{n}^{2} / C_{n+m}^{2}$, on the second- $C_{m}^{2} / C_{n+m}^{2}$. Accordingly, the portion of a heterozygous (heteroallelic) genotype is determined with the formula $C_{n}^{1} C_{m}^{1} / C_{n+m}^{2}$. These formulas show the phenotypic ratio in portions from one. However, these ratios can be expressed also with simple numbers which are to be determined the following way: for the first homoallelic genotype - as $n(n-1): 2$, for the second homoallelic genotype-as $m(m-1): 2$ and for the heteroallelic genotype-as $n m$.

The revealed experimental ratios were compared to the theoretically expected using criterion $\chi^{2}$. The choice of the polygenotype was made according to the minimal $\chi^{2}$ value. 


\section{RESULTS AND DISCUSSION}

Seed progenies were obtained from all three experimenttal sugar beet plants. We consider these progenies as agamospermous on the base of the previous and numerous data obtained with various methods, which are indicative of the fact that the growth method we used for pollensterile sugar beet plants in the pollenless regime allows us to obtain an agamospermous progeny [14-17]. For example, to prove the agamospermous origin of the progeny, we used unopened buds castration with their further isolation [13], natural sampling method consisting in the analysis of seed phenotypes in the sequence they were setting on plant branches [18], revealing specific seed phenotypes ratios explained only by the agamospermous origin of the analyzed progeny [15], obtaining the genetic proofs for the absence cross-pollination between growing sterile and semisterile sugar beet plants [17].

Polymorphism on two out of three marker enzymes -alcohol dehydrogenase (ADH1), malic enzyme (ME1) and isocitrate dehydrogenase (IDH3) (Table 1) - was revealed in each investigated agamospermous sugar beet progeny. The presence of polymorphism points out heterozygosity of the initial mother plants on the corresponding enzyme loci. The phenotypic ratio on ME1 in the progeny produced from plant $2-7$ under the parchment isolator is significantly different from ratio 1:2:1 $\left(\chi^{2}\right.$ $=7.6 ; \mathrm{P}<0.05)$ typical of self-pollinated progenies. Besides, the ratio of the total homoallelic phenotypes portion to that of the heteroallelic phenotype is significantly different from ratio $1: 1\left(\chi^{2}=7.2 ; \mathrm{P}<0.01\right)$ typical of the progenies produced by self-pollination. This is one more proof for the agamospermous origin of the progenies we analyzed. This conclusion allowed us, further on, to evaluate the degree of heterozygous locus alleles polyteny in mother plant cells.

The use of isolators in obtaining sugar beet seed progenies from pollen-sterile plants leads to low seed pro- ductivity. As a consequence of this, it is not always possible to obtain big samples (number of seeds) for the genetic analysis.

G-criterion-assisted comparison of the phenotypic classes ratios of seed progenies obtained at different ways of isolation, in most cases, did not reveal significant differences. This allowed us to integrate the samples of one and the same plant and to determine marker locus polygenotypes in mother plant cells on the integrated samples.

Several values of polygenotypes, but with a different probability, corresponded to the integrated ratios of phenotypes. For instance, several possible polygenotypes$F_{4} S_{6}\left(\chi^{2}=2.8244\right) ; F_{5} S_{7}\left(\chi^{2}=1.9592\right) ; F_{6} S_{8}\left(\chi^{2}=1.9120\right)$, out of which the last is the most probable one-correspond to the integrated ratio on ME1 being 22FF:59FS:45SS in the KA-8 plant progeny. This polygenotype means that locus $M e 1$ is presented by two chromosomes in mother plant cells, in one of which allele $M e 1-F$, as a result of polytenization, is presented by six copies and allele Me1$S$-by eight, respectively. In the same progeny, polygenotype $F_{6} S_{5}\left(\chi^{2}=0.0044\right)$ mostly corresponds to the integrated ratio on IDH3 (31FF:62FS:21SS).

In the progeny of plant $12-2$, polygenotype $F_{8} S_{7}\left(\chi^{2}=\right.$ 1.6173) mostly corresponds to the integrated ratio ADH1 $30 \mathrm{FF}: 46 \mathrm{FS}: 22 \mathrm{SS}$ and, in the same progeny, polygenotype $F_{8} S_{7}\left(\chi^{2}=0.5268\right)$ mostly corresponds to the integrated ratio on ME1 equal to 27FF:49FS:22SS.

The sample size of the seeds for ME1 analysis in the progenies of plant 2 - 7 obtained under different isolators is also not big. However, the difference in phenotypic classes ratios is so considerable $(\mathrm{G}=220.8436$; $\mathrm{P}<$ 0.001 ) that this allowed us to determine the polygenotypes individually corresponding to each seed group. Polygenotype $F_{2} S_{2}\left(\chi^{2}=2.2\right)$ mostly corresponds to the ratio on ME1, being 1FF:16FS:3SS, revealed in the seeds obtained under the parchment isolator, and polygenotype $F_{8} S_{7}\left(\chi^{2}=1.4539\right)$ mostly corresponds to ratio $10 \mathrm{FF}$ :

Table 1. Ratio of marker enzymes phenotypic classes in agamospermous sugar beet progenies and polygenotypes $\left(F_{n} S_{m}\right)$ of mother plant cells capable of embryogenesis.

\begin{tabular}{|c|c|c|c|c|c|c|c|}
\hline \multirow{2}{*}{ № of plant } & \multirow{2}{*}{ Type of isolator } & \multicolumn{2}{|c|}{$\mathrm{ADH} 1$} & \multicolumn{2}{|c|}{ ME1 } & \multicolumn{2}{|c|}{ IDH3 } \\
\hline & & FF:FS:SS & $F_{n} S_{m}$ & FF:FS:SS & $F_{n} S_{m}$ & FF:FS:SS & $F_{n} S_{m}$ \\
\hline \multirow[b]{2}{*}{ КА-8 } & Parchment & $62: 0: 0$ & \multirow[b]{2}{*}{ - } & $11: 35: 23$ & \multirow[b]{2}{*}{$F_{6} S_{8}$} & $15: 40: 12$ & \multirow[b]{2}{*}{$F_{6} S_{5}$} \\
\hline & Unbleached calico & & & $11: 24: 22$ & & & \\
\hline \multirow[b]{2}{*}{$12-2$} & Parchment & $21: 22: 9$ & \multirow[b]{2}{*}{$F_{8} S_{7}$} & $13: 27: 11$ & \multirow[b]{2}{*}{$F_{8} S_{7}$} & 10:0:0 & \multirow[b]{2}{*}{ - } \\
\hline & Unbleached calico & $9: 24: 13$ & & $14: 22: 11$ & & Not analyz. & \\
\hline \multirow{2}{*}{$2-7$} & Parchment & Not analyz. & \multirow[b]{2}{*}{ - } & $1: 16: 3$ & $F_{2} S_{2}$ & $6: 5: 3$ & \multirow[b]{2}{*}{$F_{6} S_{5}$} \\
\hline & Unbleached calico & $31: 0: 0$ & & $10: 14: 7$ & $F_{8} S_{7}$ & $5: 16: 5$ & \\
\hline
\end{tabular}


$14 \mathrm{FS}: 7 \mathrm{SS}$ in the seeds from the unbleached calico isolator.

Drastic differences in cell polygenotypes belonging to the plant branches, being under different isolators indicate, that external (environmental) conditions affect polytenization processes.

It is noteworthy that this influence depends on the genotypic medium, as it was not found in other two plants. The role of genotypic medium manifests itself also in the fact that, independent from the type of isolator, the phenotypic ratios on ME1 in the progeny of plants KA8 and $12-2$ are significantly different in the G-criterion $(\mathrm{G}=$ $6.9666 ; \mathrm{P}<0.01)$ and, hence, these plant polygenotypes are different (Table 1).

The sample size plays a considerable role in the detection of a weak response to external impacts and, in case of its (sample size) increase, the differences could, apparently, have also been revealed in most cases, just as e.g. in the progeny of plant $12-2$ in the phenotypic ratio on ADH1.

Outstanding is the fact that the calculated polytenization degree of both locus $M e 1$ alleles in plant $2-7$ is considerably lower under the parchment isolator than that under the unbleached calico. Probably, this is conditioned by the fact that the branch tissues and cells under the parchment isolator experience a strong stress and aberration of many biochemical processes as a consequence of the breakdown of light regime, also gas and temperature exchange. The conditions under the unbleached calico isolator are, probably, a bit close to natural ones, which contribute more to a normal procedure of biochemical processes including chromosome sites polytenization.

A more considerable number of polygenotypes, among which polygenotypes $F_{8} S_{7}\left(\chi^{2}=0.0156\right)$ and $F_{6} S_{5}\left(\chi^{2}=\right.$ $0.1041)$ are possible, may correspond to the integrated ratio on IDH3 being 11FF:21FS:8SS in the progeny of plant 2 - 7 due to a small sample size. Herein, due to a small sample size, polygenotype $F_{6} S_{5}\left(\chi^{2}=0.1041\right)$ was chosen, the same also for ratio $31 \mathrm{FF}: 62 \mathrm{FS}: 21 \mathrm{SS}$ on IDH3 in plant $\mathrm{K}-8$, in which this plant has no differences in criterion $\mathrm{G}$.

The calculated locus polygenotypes values with an odd polyteny level, at least of one of the alleles, correspond to the mitotic agamospermy at which the cell, having not undergone meiotic genome transformations, enters embryogenesis. This may be, for instance a nucellus or integument cell. At the same time, the phenotypic ratio that corresponds to polygenotype $F_{6} S_{8}$, may also correspond to the other polygenotype: namely $F_{3} F_{3} S_{4} S_{4}$ which is typical of the mother megaspore cell (MMC). In this case it is possible to hypothesize about the existence of such tetraploid MMCs in which one allele is presented by two chromosomes, each of which, as a consequence of polytenization, has four chromatides, and the other allele is presented by the other pair of chromosomes in which there are only three copies as a result of underreduplication. In the entering of such MMC into embryogenesis and a loss of excessive allelic copies, there emerge diploid gametes developing into individual diploid embryos (plants) at the same ratio as in mitotic agamospermy. The only difference is that, in this case, this will be a progeny obtained by meiotic agamospermy and the combinatorial process of the excessive allelic copies diminution is connected with a combinatorial process of a two-fold decrease of chromosomes number in the cell.

The obtained data confirm the existing outlook on the thing that many factors affect the polytenization process. It was shown with many cytological investigations carried out both in Drosophila and in plants that the level of chromosome polytenization depends on both internal conditions (level of inbreeding) $[25,26]$ and external conditions (temperature, daylight length) [27,28]. Our results and analogous conclusions, unlike those of cited contributions, were obtained only on the base of the data of genetic analysis. Such an unusual approach is justified, on the one hand, by the impossibility of any other explanation for the specific sugar beet phenotypic classes ratios and, on the other hand-confirmation of the hypothesis we use with the data from the field of mammalian genetic, including that of human. Abnormalities based on the presence of one-parent disomy in an individual of some chromosome pair or certain regions of homological chromosomes obtained from only one parent were found in both human and mice $[29,30]$. As we mentioned earlier, such phenomenon could appear only as a result of excessive reduplication of certain regions or whole chromatides which further led to an occasional equiprobable diminution of the excess of genetic material.

The specificity of the problem we investigated consists in the thing that it is difficult to determine the low polyteny level with the help of cytological methods, but it may be revealed in embryo sac cells or surrounding tissues only on the base of genetic calculations. Therefore, our further studies will be aimed at the use of additional methods for evaluation of the degree of chromosome polyteny in embryo sac cells and surrounding tissues.

The obtained proof for the agamospermous origin of the progenies we analyzed and additional confirmation of the hypothesis about the differential chromosomes polyteny, and its dependence on external conditions are in favor of the supposition regarding the role of polyteny in the record of information about acquired traits.

\section{ACKNOWLEDGEMENTS}

The authors would like to express their gratitude to Alexander V. 
Zhuravlev for the English version of this article.

\section{REFERENCES}

[1] Richards, A.J. (1986) Plant breeding systems. George Allen and Uniwin, London.

[2] Kashin, A.S. (2006) Gametophytic apomixis as an unstable seed reproductive system in flowering plants. Nauchnaya kniga, Saratov.

[3] Marshal, D.R. and Brown, A.H.D. (1974) Estimation of the level of apomixis in plant populations. Heredity, 32, 321-333. http://dx.doi.org/10.1038/hdy.1974.41

[4] Maletskii, S.I., Sukhareva, N.B. and Baturin, S.O. (1994) Sex inheritance in apomictic seedlings of garden strawberry (Fragaria ananassa Duch.). Russian Journal of Genetics, 30, 237-243.

[5] Maletskii, S.I. and Maletskaya, E.I. (1996) Self-fertility and agamospermy in sugar beet Beta vulgaris L. Russian Journal of Genetics, 32, 1643-1650.

[6] Maletskii, S.I., Levites, E.V., Maletskaya, E.I. and Shavorskaya, O.A. (1997) Autosegregation in the parthenogenetic offspring of sugar beets (Beta vulgaris L.). Doklady Biological Sciences, 354, 292-293.

[7] Maletskii, S.I., Levites, E.V., Maletskaya, E.I. and Ovechkina, O.N. (1998) Autosegregation and linked inheritance in the agamospermous progeny of sugar beet Beta vulgaris L. Russian Journal of Genetics, 34, 418-424.

[8] Levites, E.V. (2002) New classification of the reproduction modes in sugar beet. Sugar Technology, 4, 45-51. http://dx.doi.org/10.1007/BF02956879

[9] Schwartz, D. (1966) The genetic control of alcohol dehydrogenase in maize: Gene duplication and repression. Proceedings of the National Academy of Sciences, 56, 14311436. http://dx.doi.org/10.1073/pnas.56.5.1431

[10] Scandalios, J.G. (1969) Genetic control of multiple forms of enzymes in plants: A review. Biochemical Genetics, 3, 37-79. http://dx.doi.org/10.1007/BF00485973

[11] Levites, E.V., Shkutnik, T., Ovechkina, O.N. and Maletskii, S.I. (1999) Pseudosegregation in the agamospermic progeny of male sterile plants of the sugar beet (Beta vulgaris L.). Doklady Biological Sciences, 365, 182-184.

[12] Levites, E.V. (2005) Sugarbeet plants produced by agamospermy as a model for studying genome structure and function in higher plants. Sugar Technology, 7, 67-70. http://dx.doi.org/10.1007/BF02942532

[13] Levites, E.V. (2007) Marker enzyme phenotype ratios in agamospermous sugarbeet progenies as a demonstration of multidimensional encoding of inherited information in plants. http://arxiv.org/abs/q-bio/0701027

[14] Levites, E.V. and Kirikovich, S.S. (2011) Autosegregation of enzyme loci in agamospermous progenies of triploid plants of sugar beet (Beta vulgaris L.). Russian Journal of Genetics, 47, 836-841. http://dx.doi.org/10.1134/S102279541107012X

[15] Levites, E.V. and Kirikovich, S.S. (2012) Post-meiotic apozygotic combinatory process in sugar beet (Beta vul- garis L.). Advances in Bioscience and Biotechnology, 3, 75-79. http://dx.doi.org/10.4236/abb.2012.31011

[16] Levites, E.V. and Kirikovich, S.S. (2010) Endoreduplication as a factor of variability in sexual and agamospermous progenies of plants. Developmental Biology: The Morphogenesis of Reproductive Structures and the Role of Somatic, Stem Cells at Ontogeny and Evolution. The Partnership of Scientific Publications KMK, Moscow, 77-80.

[17] Kirikovich, S.S. and Levites, E.V. (2013) Effect of Triton $\mathrm{X}-100$ on genetic segregation and manifestation of the trait of mono- and dicotyledonousness in sugarbeet (Beta vulgaris L.). Russian Journal of Genetics, 49, 517-522. http://dx.doi.org/10.1134/S1022795413050062

[18] Levites, E.V. and Kirikovich, S.S. (2008) Using the method of natural samples for studying the variability in sugar beat (Beta vulgaris L.) agamospermous seed progeny. Russian Journal of Genetics, 44, 1296-1303. http://dx.doi.org/10.1134/S1022795408110070

[19] Owen, F.V. (1945) Cytoplasmically inherited male sterility in sugar beet. Journal of Agricultural Research, 71, 423-440.

[20] Meizel, S. and Markert, C.L. (1967) Malate dehydrogenase isozymes of the marine snail Ilyanassa obsolete. Archives of Biochemistry and Biophysics, 122, 753-765. http://dx.doi.org/10.1016/0003-9861(67)90185-3

[21] Vallejos, C.E. (1983) Enzyme activity staining. Isozymes in Plant Genetics and Breeding. Part A. Elsevier, Amsterdam, 469-515.

[22] Weber, E. (1986) Grundriss der biologischen Statistik. Gustav Fischer, Stuttgart.

[23] Haldane, J.B.S. (1930) Theoretical genetics of autopolyploids. Journal of Genetics, 22, 359-372. http://dx.doi.org/10.1007/BF02984197

[24] Feller, W. (1950) An introduction to probability theory and its applications. John Wiley and Sons, INC., New York.

[25] Pokhmel'nykh, G.A. and Shumnyi, V.K. (1984) Nature of heterochromatin knob regions of maize chromosomes: 2. Nature of changes in the knob regions under inbreeding. Russian Journal of Genetics, 20, 1649-1662.

[26] Bier, K. (1958) Beziehungen zwischen Wachstumsgeschnwindigkeit, endometaphasischer Kontaktion und der Bildung von Riesenchromosomen in den Nahrzellen von Calliphora. Zeitschrift fur Naturforschung, Section A Journal of Physical Sciences, 136, 80-93.

[27] Nagl, W. (1970) Inhibition of polytene chromosome formation in Phaseolus by polyploidy mitosis. Cytologia, 35, 252-258. http://dx.doi.org/10.1508/cytologia.35.252

[28] Nagl, W. (1973) Photoperiodic control of activity of the suspensor polytene chromosomes in Phaseolus vulgaris. Zeitschrift für Pflanzenphysiologie, 70, 350-357.

[29] Yamazawa, K., Ogata, T. and Ferguson-Smith, A.C. (2010) Uniparental disomy and human disease: An overview. American Journal of Medical Genetics Part C: Seminars in Medical Genetics, 154C, 329-334. http://dx.doi.org/10.1002/ajmg.c.30270 
[30] Cattanach, B.M. and Kirk, M. (1985) Differential activity of maternally and paternally derived chromosome regions in mice. Nature, $\mathbf{3 1 5}, 496-498$.

http://dx.doi.org/10.1038/315496a0 